\title{
Ansiedades de Influência: Teoria da Conspiração e Cultura Terapêutica na América do Milênio*
}

\author{
Susan Harding ${ }^{1}$ \\ Kathleen Stewart ${ }^{2}$ \\ Tradutor: Bruno Reinhardt ${ }^{3}$ \\ Revisora: Vânia Z. Cardoso ${ }^{3}$ \\ ${ }^{1}$ Universidade da Califórnia, Santa Cruz, CA, Estados Unidos da América \\ ${ }^{2}$ Universidade do Texas, Austin, TX, Estados Unidos da América \\ ${ }^{3}$ Universidade Federal de Santa Catarina, Florianópolis, SC, Brasil
}

\section{Resumo}

Neste capítulo de livro, publicado originalmente em 2003, Susan Harding e Kathleen Stewart analisam a explosão de teorias da conspiração nos Estados Unidos do pós-Guerra. Elas evitam o apelo comum de isolar o pensamento conspiratório como mero padrão hermenêutico exótico ou tipo de ideologia específica ao tratá-lo como parte de uma "estrutura de sentimento", "sistema nervoso" e "discurso metacultural" amplo, difuso e inclusivo, apesar de atualizado em diversas intensidades. A "ansiedade de influência", o sentimento agudo de estarmos sendo manipulados pelos próprios sistemas de expertise que sustentam a ordem contemporânea, dá vazão a uma semiótica ansiosa, obcecada pela leitura de "sinais" que desvelam uma Verdade final intencionalmente obscurecida e gera práticas encarnadas que funcionam simultaneamente como cura e sintoma. Essa estrutura paranoica de sentimento é analisada por meio de uma cuidadosa reconstituição etnográfica de duas comunidades "remanescentes": o apocalipticismo otimista da igreja pentecostal-carismática Calvary Church e o trágico, mas igualmente otimista, "plano de fuga" extraterreno do movimento de base ufológica Heaven's Gate.

Palavras-chave: Teorias de Conspiração. Estrutura de Sentimentos. Semiótica Ansiosa. Cultura Terapêutica. EUA.

\section{Anxieties of Influence: Conspiracy Theory and Therapeutic Culture in Millennial America}

\begin{abstract}
In this essay, originally published as a book chapter in 2003, Susan Harding and Kathleen Stewart analyse the explosion of conspiracy theories in the post-War United States. They avoid approaching conspiratorial thinking as a mere exotic hermeneutic pattern or ideology by treating it as part of a "structure of feeling", a "nervous system" and a "metacultural discourse" diffuse and inclusive, despite being actualized at various intensities. The "anxiety of influence", an acute feeling of being manipulated by the very systems of expertise that sustain the contemporary order, gives rise to an anxious semiotics, obsessed with reading "signs" that unveil an intentionally obscured final Truth and generate embodied practices that function simultaneously as a cure and a symptom. This paranoid framework is analysed through a careful ethnographic reconstitution of two "remnant" communities: the optimistic apocalypticism of the Pentecostal-Charismatic church Calvary Church and the tragic, but equally optimistic, extraterrestrial "escape plan" of the Heaven's Gate movement, inspired by UFO discourse.
\end{abstract}

Keywords: Conspiracy Theories. Structure of Feeling. Anxious Semiotics. Therapeutic Culture. USA. 


\section{Introdução}

Ta virada do século XX nos Estados Unidos, a neurastenia, ou "fraqueza nervosa", havia se tornado uma sintomatologia altamente popular de ansiedades caracteristicamente modernas. Seus vários sintomas - insônia, letargia, depressão, hipocondria, histeria, ondas de calor e de frio, asma, febre-de-feno, dor de cabeça, e "colapso cerebral" - marcavam graficamente os efeitos da urbanização, da industrialização e da racionalização da vida cotidiana. Sua irritante preocupação com o vigor e a decadência do corpo articulava os conflitos, as contradições e as sensibilidades assombradas que emanavam de mudanças sociais amplas e profundas (LUTZ, 1991, p. 4-5). Como uma desordem, a neurastenia encorporava [embodied] a nova sensibilidade ansiosa de um sujeito excitável como sintoma, espelho e fonte de forças mundanas; de repente, tanto o eu quanto o mundo ao redor pareciam ao mesmo tempo difusos, sem peso, flutuantes e irreais, carregados de sintomas, assombrados, imobilizados e excessivamente sensoriais e concretos (LUTZ, 1991, p. 15-16). Como discurso, a neurastenia articulou tanto o misterioso mal-estar de um sujeito afetado por processos sociais amplos e vagamente percebidos quanto o sonho terapêutico emergente de revitalização por meio da medicina, da autoajuda, da cura pela fala e das curas espirituais ecléticas.

A neurastenia era uma estrutura de sentimento instável e frágil, misturando um imaginário gótico de ameaças ocultas e forças invisíveis com o otimismo de um novo ethos consumista-terapêutico de autorrealização, magnetismo pessoal e carisma corporativo (FOX; LEARS, 1983). Tornou-se uma verdadeira língua franca cultural, não porque fornecia uma narrativa-mestra unificada para tempos ansiosos, mas porque, ao contrário, era um local de conjuntura para discursos concorrentes e conflitantes, que iam da evolução, da civilização, da ciência, da tecnologia e da medicina, da religião e da ética, do gênero e da sexualidade, da saúde e da doença, da classe e da raça até a arte e a política (LUTZ, 1991, p. 20). Ela era "uma história com vários sotaques" que permitiu muitas leituras diferentes e, ao mesmo tempo, como um discurso, ela era tanto heteroglóssica quanto "nervosa", articulando forças e sensibilidades diacríticas ou opostas (LUTZ, 1991, p. 15). Como um espaço sintomático de conjuntura em que o empreendedorismo encontrou o sentimentalismo familiar, a racionalização cultural encontrou o reencantamento, em que o consumismo, o conflito de classes, o feminismo e uma cultura terapêutica recém-profissionalizada se olharam com desconfiança, a neurastenia era num momento progressista e, no seguinte apocalíptica, ao mesmo tempo otimista e pessimista, tanto produtiva de novas formas sociais quanto agressivamente conservadora. 
Em sua produção social, a neurastenia primeiro se tornou uma língua franca cultural entre os produtores culturais da virada do século - artistas, escritores e outros "brain workers" [trabalhadores do cérebro] - homens e mulheres com "as mais refinadas sensibilidades", e depois se espalhou para outras classes e setores por meio de reações e de usos sociais particulares que a abraçavam, rejeitavam, subvertiam ou dela se apropriaram (LUTZ, 1991, p. 6, 15). Em outras palavras, como um "sistema nervoso", a neurastenia não apenas expressava ou refletia ansiedades modernas, mas também participava de sua produção particular e real como um conjunto de práticas discursivas de uso social e político (TAUSSIG, 1992; LUTZ, 1991, p. 20). Na prática, a neurastenia tanto proliferou como contestou as ansiedades da modernidade e sua racionalização da ligação entre o sujeito e um mundo de forças e efeitos.

Agora, no final de um longo século de eflorescência de sintomatologias ansiosas dentro de um sistema nervoso contínuo, a teoria da conspiração tornou-se uma nova língua franca para acompanhar as tensões e os sintomas da "Nova Ordem Mundial". Sua linguagem não é o corpo, mas o corpo político; sua preocupação com o controle não trata do vigor corporal, mas da agência humana e do conhecimento político em um mundo de influências sociais (MELLEY, 2000). Como a neurastenia, a teoria da conspiração articula tanto os sintomas quanto as curas em uma ligação ansiosa entre as misteriosas forças ocultas e a força de cura redentora da agência. Ao contrário da neurastenia, que presumia que seus sintomas eram o resultado acidental do progresso civilizacional, o pensamento conspiratório se concentra na revelação da "verdade chocante": ele assume que nossas ansiedades são projetadas [designed]. Somos as vítimas dos persuasores ocultos da cultura consumista, um complexo tecnogovernamental de longo alcance, uma rede de forças demoníacas, um enxame interminável de sofisticados controles sociais e influências invasivas. A sensibilidade da conspiração, ou "paranoia da fusão" (KELLY, 1995), rastreia signos e surtos de poder, vigia superfícies banais para descobrir ameaças e promessas ocultas, juntam detalhes díspares e obscuros em busca da chave para um quebra-cabeça final e para o momento em que o imaginário finalmente corresponde ao real. Ela sonha com caminhos excêntricos de retorno a um passado imaculado, uma agência humana redentora e um mundo ordenado do alto como se um projeto de lei, um código ou um texto unitário pudesse ser impresso diretamente, magicamente, na matéria e na sociedade, alegando curar a ferida impressa pela longa sensação de desencaixe entre o sonho americano e uma realidade sempre já degradada. É, como a neurastenia, um discurso animado de imediato pelo medo e pelo desejo.

A teoria da conspiração do pós-guerra difere dos "estilos paranoicos" anteriores da política americana em sua tendência a amplas críticas sociais e culturais. Ao invés disso, ela revela sociedades secretas, e seu julgamento quase unânime é de que o poder do governo é parte da conspiração, em vez do objeto inocente dela. Também não é mais um modo episódico ou excêntrico de atenção e articulação política. Como a neurastenia na virada do século, a teoria da conspiração da virada do milênio é uma abrangente estrutura de sentimento que articula esforços políticos conflitantes e públicos díspares em um espaço de conjuntura nacional multivocálico.

A teoria da conspiração tornou-se tão profundamente enraizada no imaginário político nacional que abrange todos os pontos do espectro político e é tão característica 
do centro quanto de grupos marginais e conhecimentos ocultos (DEAN, 1998; MARCUS, 1999). Conspirações, conluios secretos, atividades clandestinas e todo tipo de traição são acusados e frequentemente provados ou confessados. O governo federal constrói elaborados sistemas de defesa para proteger a nação contra espectros flutuantes de terrorismos catastróficos e armas de destruição em massa (LEWIS, 1999). Falam-nos de grotescas experiências secretas do governo sobre cidadãos inconscientes, similares aos experimentos com sífilis em Tuskegee com homens afro-americanos (WILSON; MILL, 1998). As principais figuras do governo, da indústria, da ciência, da medicina e dos militares são diretamente envolvidas em casos de corrupção social e política, degradação ambiental, fraude e engano ao consumidor (SCHOEPFLIN, 1998).

Relatórios investigativos, talk shows, séries de televisão, filmes, romances e livros didáticos apresentam uma sensação difusa, às vezes em pânico, de luta contra forças desconhecidas - uma profunda preocupação com o fato de a normalidade não ser mais normal, de que "alguém" fez algo ao modo como as coisas costumavam ser, de que perdemos algo, de que mudamos, ou melhor, fomos mudados. Estamos sendo influenciados, manipulados, regulados, experimentados, vigiados (GRAHAM, 1996). Então, apesar de nossas suspeitas com a polícia, nos tornamos seus agentes em resposta a projetos do tipo Community Watch, que nos solicitam vasculhar corpos estranhos na vizinhança, e a programas de televisão como o America's Most Wanted, que nos pedem para escrutinar imagens de suspeitos. A onipresente câmera de vídeo doméstica está pronta para capturar momentos de forças conspiratórias em movimento, como a brutalidade policial, encenando um panóptico omnipresente que imita a lógica do próprio "sistema". Os slogans duplos da série Arquivo X - "Não confie em ninguém" e "A verdade está lá fora" - expressam o casamento inebriante, ainda que inquietante, entre um profundo ceticismo com relação a verdades oficiais e as seduções da sensualização do poder/saber (FOUCAULT, 1980, p. 44).

A teoria da conspiração espalhou-se por tantas rotas divergentes e conflitantes que agora articula a sensibilidade amplamente compartilhada de estarmos sendo controlados por um sistema totalmente invasivo, em rede, que está fora de controle. Como a neurastenia, o pensamento conspiratório é uma história com vários sotaques, um conjunto sobreposto de discursos heteroglóssicos que conjuga reações e resultados contraditórios e competitivos em uma estrutura de sentimento que anseia desesperadamente por soluções definitivas. Ele modela visões de direita e de esquerda com igual vigor. A direita religiosa mobilizou uma nova "política das coisas últimas" [politics of ultimacy] que lê a política através de uma lente milenarista guiada por questões fatídicas colocadas em jogo em um confronto final (BARKUN, 1998, p. 459). Pat Robertson juntou-se a diferentes correntes da teorias da conspiração de direita sob a rubrica da Nova Ordem Mundial, popularizada em seu livro de 1991 com o mesmo título. A cultura da "nova guerra", masculina e branca, reagiu à feminizada Nova Ordem Mundial com um movimento cultural paramilitar centrado em filmes como Rambo, jogos de paintball, a revista Soldier of Fortune, campos de tiro, milícias e testes de sobrevivência (GIBSON, 1994). A Nova Ordem Mundial rapidamente acumulou um roteiro de ameaças incluindo novos grupos de agentes da lei contrários a proprietários de armas, vigilância por meio de helicópteros negros e microchips implantados, campos de concentração para dissidentes dirigidos pela Federal Emergency Management 
Agency, e a presença de centenas de milhares de tropas estrangeiras afiliadas às Nações Unidas em solo americano para abafar a resistência armada (BARKUN, 1998, p. 455).

Na esquerda, movimentos políticos que lutam contra as desigualdades de raça, sexo e classe assumiram as práticas da teoria da conspiração para rastrear os efeitos violentos da subjugação injusta sobre as identidades, os corpos e o corpo político. Na década de 1980, o Cristic Institute ingressou com uma ação judicial contra um grande conjunto de ex-oficiais militares e de inteligência dos EUA que constituíam uma "Equipe Secreta" que operava uma vasta empresa de contrabando de drogas e de armas e que tinha estado diretamente envolvida em muitos dos infelizes eventos da história americana desde a década de 1950 (KELLY, 1995, p. 69). Mais recentemente, uma ampla coalizão de grupos ambientalistas, igrejas liberais, trabalhadores e ativistas de movimentos sociais lançou uma campanha internacional contra a Organização Mundial do Comércio como uma potência mundial secreta e conspiratória. Teorias conspiratórias que circulam na esfera pública negra afirmam que o HIV foi disseminado em bairros negros com o propósito de promover o genocídio, que o governo intencionalmente espalhou narcóticos em comunidades negras, que aditivos alimentares no Kentucky Fried Chicken esterilizaram sistematicamente homens negros, mas não homens brancos (FENSTER, 1999, p. 72; KELLY, 1995, p. 64). Alguns discursos feministas seguiram os rastros de conspirações para o domínio masculino por meio de instituições, ideologias e vida privada (KELLY, 1995, p. 64), enquanto o movimento masculino [men's movement] abraçou os homens como feridos pelo mesmo regime patriarcal e buscou soluções terapêuticas (PFEIL, 1995).

Todas as vozes teorizando conspiração, Direita, Esquerda e aqueles "difíceis de rotular", tomam por certo que os poderes estabelecidos são funcionários do campo adversário, e nenhum supõe que a política de rotina oferece muito, se algum, remédio ("expulsem os bastardos"). Pois a conspiração do pós-guerra diagnosticou problemas estruturais e não de ordem pessoal. É a expressão nervosa da ideia de que os sistemas sociais afetam a ação humana, que grandes organizações, burocracias, instituições sociais, redes de informação, ideologias e discursos moldam os indivíduos e que, portanto, não somos indivíduos inteiramente livres, autônomos e autogeridos (MELLEY, 2000, p. 5). Na teoria da conspiração, a regulamentação social vem como uma terrível revelação, um escândalo, devido ao desafio que ela apresenta, e a ameaça que ela representa, às antigas noções do indivíduo como um agente coerente, racional e autônomo. Não só as coisas não são como antes, mas "as pessoas não são mais o que costumavam ser" (MELLEY, 2000, p. 42). As interpretações paranoicas do pós-guerra estão, portanto, enraizadas em e articulam "pânicos de agência" (MELLEY, 2000, p. 12). Ao mesmo tempo, elas efetuam uma "transferência pós-moderna" na qual a agência depauperada do indivíduo é atribuída ao social. As estruturas sociais não simplesmente afetam a ação humana; elas são misteriosas, motivadas, intencionais e frequentemente malévolas (MELLEY, 2000, p. 13).

Indivíduos, grupos e organizações de tempos em tempos ficam tão enredados em suas visões conspiratórias que as colocam em prática, às vezes de forma violenta. Charlie Manson, Timothy McVeigh, Theodore Kaczynski, milícias supremacistas brancas, o FBI de J. Edgar Hoover, os Branch Davidians e a ATF em Waco são exemplos sensacionais, mas todos nós vislumbramos em algum lugar - em nossas famílias, escolas, locais 
de trabalho e comunidades - aquele olhar hiper-vigilante e paranoico, aquela raiva sem fundo contra o sistema, aquela compilação obsessiva de sinais de que "eles" não servem para nada. Pode parecer que esses momentos mais e menos sensacionais são os únicos momentos em que alguém parece fazer algo sobre conspirações, que de outra forma é só conversa, muita conversa selvagem, que nunca gera nada, como as válvulas liberando vapor, os efluentes da vida pós-moderna. Mas a conversa sobre conspirações do pós-guerra nunca é ociosa. É sempre algum tipo de terapia que tem temas relativos ao fim último e à redenção embutidos - como sonhos, realidades abismais ou estruturas inconscientes intensamente polarizadas. As práticas da teoria da conspiração formam um pacto tenazmente articulado com a cultura terapêutica por meio das lógicas do estresse, do trauma, da injustiça, da autoagência e da redenção. Tomadas separadamente e em conjunto, a teoria da conspiração e a cultura terapêutica constituem campos de sentimento que canalizam as contradições das transformações sociais contemporâneas e seus efeitos. Elas unem desejo e desespero, progresso e colapso, encantamento e desencanto, saudades nostálgicas e desejos futuristas, e a busca de tudo, da pureza à comunidade. Essa é a natureza de um sistema nervoso moderno. É também a natureza dos metadiscursos da modernidade.

A cultura terapêutica surgiu com a mudança para o capitalismo de consumo na virada do século. Ela substituiu a ética do trabalho, do sacrifício e da economia por um anseio de autorrealização enraizado no sentimento neurastênico de que a pessoalidade tornou-se fragmentada, difusa e de alguma forma "sem peso" ou "irreal". A publicidade, as diversões de massa em busca do emocionante e uma ética da gratificação imediata ajudaram a criar um novo universo simbólico, em que o anseio de experimentar a "vida real" em toda a sua intensidade foi tanto projetado como um ideal e frustrado pelas contradições de uma espontaneidade deliberada, midiatizada e impulsionada pelo mercado (FOX; LEARS, 1983). As reações terapêuticas contra a racionalização modernista da cultura eram, em si mesmas, sintomas da racionalização dos profissionais do cuidado, da cura pela fala e de um "eu" autônomo cujo espírito interior imanente buscava expressão e libertação.

A cultura terapêutica e a teoria da conspiração se entrelaçam por meio dos usos separados e às vezes conflitantes ou concorrentes que fazem de um conjunto compartilhado de práticas interpretativas modernistas que opõem as forças do racional ao irracional, do transparente e verdadeiro ao arcano e oculto. Com uma paixão que beira a epistemofilia, ambas reivindicam um prazer sublime no conhecimento revelado e no domínio hermenêutico, no esforço de descobrir e de recuperar o conhecimento perdido ou secreto, quebrando códigos, peneirando por meio de signos, sintomas e teias de sentimento sobredeterminados em busca do detalhe revelador. Ambas racionalizam a ligação entre o sujeito e o mundo na busca por signos de agência, disfunção e ajuste e da coleta de signos díspares em um drama narrativo de transformação, encontro, risco e conversão. Ambas descobrem uma trama subjacente que combina a dúvida radical com a sensação de que a verdade está lá fora. Nascidas da inquietação e das obsessões da modernidade que operam simultaneamente pela excitação e dormência, alarme e anestesia, contenção e celebração do autocontrole - ambas gestam disciplinas e compulsões e assumem vida própria (BERLANT, 1996; BUCK-MORSS, 1993; 1995; FELDMAN, 1994; IVY, 1993; 1995; TERKEL, 1988). 
A teoria da conspiração como prática terapêutica aborda especificamente as ansiedades modernas sobre as perfídias do poder/saber: incertezas sobre as causas e as ligações entre a ação humana e os eventos sociais complexos; sobre "expertise" e "especialistas"; sobre "verdade" e "significado" e "realidade"; sobre as grandes metanarrativas que deram direção e propósito à história; sobre como viver como um sujeito liberal (homem) preso no corpo de um sujeito sociológico (mulher/barata). No mesmo instante em que a teoria da conspiração aborda essas ansiedades, ela as produz, pois toda cura paranoica é também um sintoma. Sempre que o pensamento conspiratório afirma "a verdade" e apreende "a realidade", ele reconhece simultaneamente sua instabilidade e parcialidade, sua construção social e regulamentação. A cultura da paranoia do pós-guerra articula uma crise de agência, do sujeito liberal em perigo, mas todo esforço para restaurálo, para repudiar a sujeição, é assombrado por traços de influência (BUTLER, 1997). O conhecimento da influência social é sempre incorporado ao sujeito pós-paranoico. A incessante varredura por signos, a quebra de códigos e o domínio da lógica são um bálsamo, racionalizando, fazendo sentido, revelando o significado das coisas e, ao mesmo tempo, agitando, desestabilizando e desmembrando impérios de conspiração. A pletora de narrativas conspiratórias antidomínio [anti-master] que se apressaram a preencher o vácuo criado pela incredulidade pós-moderna com relação a narrativas grandiosas também ressalta e intensifica o sentimento de fragmentação e de desorientação histórica. A cultura paranoica é, portanto, uma terapia de compulsões. Nada é acabado. Tudo está sempre começando de novo, preso em um ciclo de repetição interminável, porque cada reencantamento encanta o encantado, cada ato autônomo é o efeito da subordinação, cada passo para fora é também sempre um passo para dentro.

Assim como a neurastenia na virada do século, descrevemos a teoria da conspiração nos Estados Unidos contemporâneos como uma ansiedade encarnada que articula as tensões, as contradições e os sonhos de redenção de um sujeito sob a influência de campos de força sociais, políticos e discursivos difusos e assombrosos. Também consideramos a cultura paranoica do pós-guerra como sendo um sistema nervoso ou uma estrutura de sentimentos. Internamente dividida entre pesadelo e sonho, sintoma e cura, torna-se um espaço liminar de conjuntura de miríades de discursos, posicionamentos e reações. Finalmente, notamos que, como a neurastenia, o pensamento conspiratório é um discurso metacultural que envolve questões fundamentais de medo e desejo, subjetividade e agência, ideal e realidade, por meio de práticas de ruminação ansiosa: a varredura por signos, sintomas e fontes de disfunção; conhecimento fetichista; experiências de enraizamento do sinistro [uncanny] e do desconhecido em estruturas ocultas e difusas de poder; deslizando em direção à redenção. Em outras palavras, tomamos a cultura da paranoia como sendo uma articulação metacultural da própria ansiedade de influência.

Culturas particulares, grupos e públicos articulam a ansiedade de influência de forma diferente e em graus variados. Eles invariavelmente reciclam e revisam tropos e enredos preexistentes, frequentemente contribuem com pequenas inovações para o campo maior do pensamento conspiratório, e, às vezes, realizam avanços impressionantes, ousando fazer conexões que ninguém tinha feito antes. Aqui, retomamos dois estudos de caso em que a estrutura paranoica de sentimento do pós-guerra é encaixada em uma gama mais ampla de práticas que moldam comunidades "remanescentes". Ambos os sistemas 
nervosos são impressionantemente inventivos e generativos, metaculturais e metafísicos, assombrados e sonhadores; ambos peneiram por meio de signos e de influências de formas complexas, críticas, assombrosas e maravilhadas; e ambos estão especialmente preocupados com o conhecimento moderno mediado e a "informação". Eles registram efeitos, decifram significados, preveem futuros e constroem histórias - pequenas, médias, grandiosas e cósmicas. No caso da Calvary Chapel, uma teoria da conspiração do século XIX recebe nova vida em uma forma terapêutica que meticulosamente faz malabarismos de luz e sombra, medo e desejo, indignação e segurança, e que proporciona uma visão da agência - a redenção terrena - por meio do conhecimento político. Na Heaven's Gate, temos um caso de terapia em movimento no qual a agência/redenção terrena é alcançada por meio da canalização milagrosa e da justaposição de diversos conhecimentos metafísicos, tanto seculares como religiosos, em autoridade carismática e um drama convincente e realmente real de vida e morte.

\section{Calvary Chapel}

Em 1997, fizemos trabalho de campo na igreja Calvary Chapel em Orange County, Califórnia. Iniciada pelo Pastor Chuck Smith em 1965, a Calvary Chapel cresceu rapidamente como parte do "Movimento de Jesus" [Jesus Movement] dos anos de 1970 e do crescimento das igrejas evangélicas suburbanas nas últimas duas décadas (BALMER, 1993; BALMER; TODD JR., 1994, p. 664). Ela combina um fundamentalismo conservador, incluindo uma interpretação rigorosa da Bíblia como a palavra de Deus e uma visão apocalíptica do fim dos tempos, com um pentecostalismo suave, ou leve, e um estilo marcadamente moderno e juvenil. No início dos anos de 1970, a Calvary Chapel atraiu convertidos entre os jovens e hippies descontentes por meio de festivais cristãos de rock, go-go clubs, love-ins, cafés cristãos, clubes de surf, batismos no oceano, e linhas telefônicas diretas para jovens em "viagens ruins" [bad trips], incluindo uma cura de 30 segundos para o vício em heroína. Hoje, o campus de Costa Mesa possui uma congregação de 25 mil membros e gerou uma federação frouxa de 400 igrejas, muitas delas com congregações de mais de dez mil pessoas (BALMER; TODD JR., 1994, p. 693).

Como muitas das novas megaigrejas evangélicas que se destacaram nos anos de 1980 e 1990, os cultos, o estilo de pregação e a estrutura da igreja adaptaram a cultura terapêutica secular para fins cristãos (MILLER, 1997, p. 21 ; HARDING, 2000), fornecendo aconselhamento matrimonial e um amplo conjunto de grupos de apoio semanais e grupos de estilo de vida, incluindo o Grupo de Estudo Bíblico da Vida Alegre das Mulheres Trabalhadoras, Aula de Provérbios para Homens, Reunião de Oração das Mães do Ensino Médio, Bolsa de Estudos Coreana, Tornando-se Discípulos (para novos crentes), Novo Espírito: Recuperação do Álcool e das Drogas, Grupo de Solteiros, Companheirismo na Prisão, Companheirismo para Deficientes Físicos, Anciãos Oram pelos Doentes e Outras Necessidades, Estudo Bíblico para Meninas do Ensino Médio, e a Reunião de Atualização da Profecia Cristã. As livrarias dessas igrejas estão repletas de uma combinação de títulos apocalípticos alertando para os perigos do individualismo utilitário e da decadência dos padrões morais sob o regime do humanismo liberal, do consumismo, da burocratização, 
assim como livros de autoajuda cristã com títulos como Devoções Diárias, Todos os Dias com Cristo, Autoconfrontação, Manual para o Discipulado Profundo, Casamento como foi feito para ser e Homens que as mulheres amam amar (uma parodia com o livro de autoajuda secular mais vendido, Mulheres que amam demais).

Os cultos começam com concertos de música pop cristã, com guitarras, bateria e grandes telas que projetam a letra da música para que a congregação possa cantar junto. O sermão que se segue é realizado em um estilo informal e vernacular; a retórica se move facilmente, oscilando entre o grande esquema da profecia bíblica, os eventos mundiais e a intimidade atual da vida privada, escolhas de estilo de vida, fé e sonhos. Um boletim de boas notícias de conversões em massa e eventos familiares divertidos passa para uma crítica suave dos valores consumistas e da ética situacional do laissez-faire em que "não há absolutamente nenhum absoluto"; o mundo está em uma constante decadência moral, e a igreja está se tornando mais mundana, portanto, os cristãos têm que mudar o mundo. Congregados vestidos com jeans e camisetas, eles leem as escrituras na versão Nova Bíblia do Rei Jaime, comercializada como a "Versão Slim Line", enquanto o pastor a cita, apimentando seus comentários com piadas da moda, sorrisos amigáveis e traduções dos sinais do fim dos tempos em termos da vida cotidiana suburbana.

O pastor encoraja as pessoas a tomar notas enquanto lhes dá dicas de como serem cristãos em um mundo que se aproxima do apocalipse. Por exemplo, ele pode oferecer um plano básico de ação cristã em três etapas: (1) seja cristão, e aja como um modelo para os outros; (2) aproxime-se dos não cristãos; e (3) fale sobre isso. Ele dá dicas concretas que misturam autoajuda com planejamento intencional e conspiratório: “É mais fácil começar um incêndio com pessoas que já estão sedentas", então tente falar com não cristãos em festas de feriados, quando o espírito estiver no ar. Todos nós precisamos sair de nossos estilos de vida suburbanos e cristãos: almoçar com um colega de trabalho ou convidar vizinhos para jantar, convidar homens não cristãos para assistir ao jogo com você, fazer contatos quando você está fazendo exercícios ou em eventos infantis, contatar pessoas que você conhecia - “embora alguns digam que é melhor não procurá-los, entende o que estou dizendo?" - e praticar "consumismo estratégico, como ir à mesma lavanderia todos os dias para aprender o nome do dono". O pastor também pode sugerir que as pessoas escrevam os títulos dos livros de autoajuda cristã "que lhes permitirão fazer estas coisas", como o trio de livros de Paul Little: Saiba no que você acredita, Saiba porque você acredita, e Como dar a sua fé a outros. Todo cristão deve ser capaz de transmitir o Evangelho em frase feita de 30 segundos a um minuto.

O apocaliticismo otimista da Calvary Chapel - otimista porque sinaliza o cumprimento da profecia bíblica, o arrebatamento e a Segunda Vinda de Cristo - lê signos de desgraça iminente em uma variedade de eventos aparentemente "bons" e "maus", incluindo o crescimento ou desenvolvimento da população mundial, educação, tecnologia, comunicações, transporte, secularização e ecumenismo, o surgimento de cultos satânicos e falsos profetas, a crise da AIDS, o movimento Nova Era, o aborto, a pornografia, a homossexualidade, o divórcio, o crime, as drogas, os OVNIs e a abdução por extraterrestres (HARDING, 2000, p. 241). O apocaliticismo para cristãos como estes não é apenas um conjunto de crenças, mas um modo narrativo específico de ler a história para trás. Eventos futuros, que são fixos e conhecidos, determinam a forma, o conteúdo e o significado dos 
eventos e ações atuais (HARDING, 2000, p. 230). Os eventos econômicos e políticos são lidos como o cumprimento da profecia bíblica que narra o retorno dos judeus à Palestina; a ascensão do Novo Império Romano; a grande tribulação durante a qual o Anticristo, ou a Besta do Apocalipse, ascenderá ao domínio mundial; o arrebatamento da igreja, quando os salvos serão poupados dos dias horríveis iminentes; o retorno triunfante de Cristo na batalha do Armagedom; e o reinado final, glorioso e milenar de Cristo em Jerusalém (FENSTER, 1999, p. 155; MARSDEN, 1980). Eventos mundiais recentes de interesse específico para as atualizações das profecias da igreja incluem, por exemplo, a Guerra do Golfo Pérsico, qualquer coisa relativa ao destino de Israel e dos judeus, como o Tratado de Paz do Oriente Médio, a eleição e reeleição de Bill Clinton, a queda do Muro de Berlim, a criação da Comunidade Econômica Europeia (o Novo Império Romano), e sinais de uma Nova Ordem Mundial em notícias da Internet, negócios e finanças transnacionais, o fim da América como potência econômica e política, e o Acordo de Livre Comércio da América do Norte (HARDING, 2000, p. 233). De acordo com a leitura da Bíblia pela Igreja, estamos atualmente na Era da Igreja - um tempo suspenso de espera e de observação - e os cristãos são ordenados a promulgar seu papel no plano de Deus, orando, vivendo corretamente e salvando almas.

Como a cultura terapêutica e a teoria da conspiração, as práticas da Calvary Chapel de interpretar oscilando entre profecia bíblica e signos no presente encontram o futuro no presente, o invisível no visível, e a redenção em uma transformação dramática. Em sua escatologia, o Fim não é meramente iminente; ele é imanente - presente em toda a história - e a vida individual mantém a promessa do Fim (FENSTER, 1999, p. 177). Nas palavras do Pastor Chuck Smith (1997), “O tempo é curto. Acredito que Deus intentou e deliberadamente projetou que cada geração deveria acreditar que Jesus está vindo em sua geração. Que cada geração tivesse essa consciência do imediatismo do retorno de Jesus Cristo. Acho que Deus projetou dessa forma" (SMITH, 1997). A promessa extasiante de eventos predestinados leva práticas interpretativas cristãs concretas a serem vistas como uma experiência transcendente do sublime; praticar a fé, aderir a princípios morais, evangelizar, consumir interpretações proféticas, procurar sinais nos eventos atuais, e aprender a sentir a vinda do Fim dos Tempos, tudo isso traz a marca de uma ordem superior realizada no cotidiano. Como os calvinistas de Weber, os seguidores da Calvary Chapel são orientados tanto a se apegar à sua fé na salvação, demonstrando-a em oração e piedade orientada para o outro mundo, quanto a construir, provar e justificar seu estado de graça por meio da ação no mundo. A crença na profecia bíblica predestinada e no arrebatamento pré-milenar dos salvos reproduz o paradoxo da predestinação calvinista dos eleitos; em vez de roubar os cristãos de sua agência, ela os infunde com a agência divinamente inspirada (WEBER, 1958, p. 111-14).

Como a cultura terapêutica e a teoria da conspiração, então, o pré-milenarismo da Calvary Chapel racionaliza a ligação entre o sujeito e o mundo, santificando a prática da busca por signos do fim dos tempos e inventando formas de ação apropriadas. Quando conecta os detalhes banais da vida cotidiana a uma ordem invisível, ele dá voz e razão a uma densidade assombrosa de efeitos flutuantes, canalizando estranhas ressonâncias e forças latentes em possíveis rotas de engajamento e salvação. Alimentado por uma dialética instável de desilusão e reencantamento, ele constitui um espaço de conjunção 
em que teorias de uma Ordem Mundial dividida entre as forças do bem e do mal, entre agência apropriada e passividade ou disfunção, se encontram com os sonhos extasiados de um ajuste pacífico e não assombrado entre o eu, a sociedade e o Espírito. Sua própria loucura, de um ponto de vista humanista moderno e secular, a torna convincente do ponto de vista bíblico; anunciá-la torna-se um ato político de dissidência, perturbação e crítica das teorias dominantes da história (HARDING, 2000, p. 238), ao mesmo tempo em que reivindica uma nova sociedade de cristãos.

A ligação nervosa entre as práticas da teoria da conspiração e a cultura terapêutica foi demonstrada mais dramaticamente nas reuniões semanais de Atualização da Profecia Bíblica da Calvary Chapel. O grupo de estudos era frequentado por um núcleo duro de teóricos da conspiração de direita que davam voz a opiniões extremistas que não foram elaboradas de outra forma na poética suave e suburbana do discurso oficial da igreja. O grupo de estudos seguia um formato padrão e ritual, que passava de uma oração de abertura a relatos alarmantes e vitriólicos de conspirações humanistas seculares, e de volta ao evangelho das Boas Novas, do arrebatamento e das injunções para que os cristãos vivessem vidas calmas e santas, de oração, preparação da alma e evangelização. O líder do grupo abria as expressões conspiratórias com um monólogo sobre as forças malévolas evidentes no Controle Federal de Armas, Bíblias unisex, ambientalismo, educação sexual nas escolas e a disseminação da homossexualidade por meio da mídia. Depois, o grupo assistia a um vídeo de um noticiário cristão, profissional, de aspecto oficial, como o Jack Van Impe Presents (com Jack e sua esposa, Rexella, posicionados em um "balcão de notícias" como âncoras) ou This Week in Bible Prophecy (estrelado por Peter e Paul LaLonde). Isso era seguido por uma fita de uma transmissão de rádio cristã profética, como a Today in Bible Prophecy, de Charles Taylor.

A tensão na sala se espessava com a justa indignação de assistir ao desdobramento de revelações chocantes e malignas. Então, o líder do grupo convidava os participantes a testemunhar sobre as atualizações em suas próprias vidas. As pessoas contavam histórias violentas de forças obscuras trabalhando em suas próprias vidas e teorizavam sobre tendências culturais, políticas e econômicas conspiratórias. Elas frequentemente expressavam dúvidas sobre sua própria inteligência e sobre a capacidade do homen comum de rastrear os movimentos misteriosos dos poderes que estão sendo exercidos. Mas tinham certeza de uma coisa: que havia forças irracionais e conspiratórias em ação no mundo e que Deus tinha um plano que daria a volta por cima no final. Quando a amargura da teoria da conspiração tinha atingido um pico insuportável, o líder afastava o grupo do chamado nascente para a ação violenta e voltava para um registro cristão terapêutico, lembrando-lhes que todas essas más notícias eram, na verdade, boas notícias, porque significava que o Senhor estava chegando em breve. O seu papel como cristãos evangélicos era simplesmente o de ir para casa e orar. Logo eles seriam liberados do conhecimento tortuoso do mal, da injustiça e das disfunções sociais. Com isso, a tensão na sala esvaziava visivelmente, e a sensação de alívio, prazer e propósito se tornava palpável. No final, a dialética encenada durante toda a sessão entre a indulgência na raiva e comentários maliciosos sobre os "idiotas" no poder e uma atitude de autocontrole cristão transcendente chegava a um ponto de descanso satisfatório. 
Durante as sessões, tanto a sensibilidade conspiratória quanto a terapêutica eram alimentadas pelos sonhos de uma agência individual triunfante que se levantava para combater a hegemonia das indústrias do conhecimento. O aumento do conhecimento no mundo é, por si só, prova da iminência do fim dos tempos; o tempo avança rapidamente e essa geração é completamente diferente de todas as outras. O conhecimento tem dobrado em uma séries de períodos cada vez mais curtos (os anos 1-1750; 1750-1900; 1900-1950; 1950-1960); nos tempos atuais, o conhecimento está dobrando a cada dois anos. Mas, na nova ordem secular e consumista das coisas, entretenimento, velocidade e comodidade são os únicos valores que se quer ver, e a mudança é tomada como um bem em si mesmo. Os papéis e os modos de vida tradicionais estão materialmente corroídos pela dependência das indústrias do conhecimento, tidas como um Deus mundano. As crianças que gastam todo o seu tempo em jogos de computador não jogam mais amarelinha e esconde e esconde. Os pais e os professores não são mais os contadores de estórias; enormes conglomerados de mídia os são. Os cristãos são advertidos a resistir às seduções e às distrações de um mundo saturado pela mídia. Na noite de filme, a igreja exibe vídeos de terror cristãos que retratam cenários em que os adolescentes perdem o voo para o arrebatamento porque são distraídos por um walk-man e não ouvem a chamada final de embarque; os empresários perdem o avião porque estão em seus celulares e computadores portáteis fazendo negócios ou jogando videogames.

Os cristãos têm que aprender a ler nas entrelinhas a fim de resistir à lavagem cerebral dos falsos profetas. Os nazistas fundaram a ciência da semântica; hoje, eles seriam capazes de usar a publicidade da Madison Avenue e a magia de Hollywood. O fato de que o crime tem diminuído, mas as denúncias de crime estão subindo, é muito conveniente para o lobby antiarmas.

As autoridades sabiam tudo sobre as bombas no World Trade Center e em Atlanta. Houve ligações para a linha direta do FBI em Atlanta e fotografias de um homem a vasculhar a sacola que guardava a bomba - será que ele a estava reiniciando? Por que eles não encontraram esse cara? Por que eles arruinaram a reputação do segurança em vez disso - o fraco? Eles são como os nazistas que queimaram o Reichstag e culparam os judeus. Uma "especialista" Nova Era na televisão declara alegremente que estamos pulando um estágio da evolução, livrando-nos de milhões de pessoas fracas; ela sugere que somente os "aptos" sobreviverão. Alguns computadores foram roubados da agência de segurança dos EUA e oferecidos para Hussein; felizmente, um hacker salvou o dia no último minuto, mas também há maus hackers por aí e vazamentos de dados alarmantes todos os dias. O mesmo cara ainda está comandando as coisas - o pequeno cara no terno vermelho.

Os falsos sistemas de conhecimento, à deriva em um mundo sem tradição e sem valores cristãos, têm produzido reivindicações ridículas e irracionais que se apresentam como valores hegemônicos e de senso comum. Sob o novo regime do politicamente correto nas escolas, por exemplo, é dito às crianças que a chuva ácida e o aquecimento global são culpa de seus pais. As crianças podem ser mandadas para casa da escola por distribuir convites de aniversário somente aos garotos. Há o ensino obrigatório da homossexualidade como um "estilo de vida alternativo" normal e saudável. (Alguém grita "Por que a milícia não pode ser um estilo de vida alternativo?" e todos riem). Hoje 
em dia, o computador de um homem pode sugerir que ele chame sua mulher [wife] de esposa [spouse ${ }^{l}$ ], e a história de Pedro e o Lobo é de repente sobre uma espécie em extinção. A eutanásia é apresentada na grande mídia como uma história de Picket Fences ${ }^{2}$ sobre um homem velho que queria ser morto para dar a seu filho seu coração. Uma pessoa com sarampo pode ser colocada em quarentena, enquanto uma pessoa com AIDS não pode sequer ser legalmente identificada. Os malucos do controle de armas querem proibir até brinquedos que se assemelham a armas ou proibir as pessoas de possuírem uma arma se alguma vez cometeram um crime, mesmo que esse "crime" não seja mais do que uma "briga verbal com sua esposa" ou uma briga na escola. Os regimes de conhecimento do mundo vêm e vão, e as velhas maneiras de pensar são sempre deslegitimadas no final. Nos anos de 1950, as pessoas usavam máquinas de raio X como um artifício de vendas para ver se seus sapatos se encaixavam, e ninguém tinha a menor ideia de que eles estavam sendo expostos a radiações nocivas. Agora, toda vez que os cientistas encontram um micro-organismo em Marte, as pessoas acreditam que há vida inteligente no universo. Ainda há coisas sobre as quais não sabemos nada, mas a profecia bíblica é uma constante.

As transmissões de notícias cristãs captam eventos mundiais críticos que a grande mídia perde porque se distrai com escândalos de novela ou ativamente os encobrem. Há leis que estão sendo promulgadas e que um dia irão sobrepor-se à soberania nacional. As doenças mortais que agora são resistentes aos antibióticos estão se espalhando sem controle. A polícia agora confisca todos os bens de uma pessoa se ela encontrar uma planta de maconha em qualquer lugar perto de sua casa (e, é claro, a polícia recebe sua parte). Eles poderiam vencer a guerra às drogas facilmente, mas não querem fazê-lo porque é apenas uma desculpa para nos controlar. Você pode ser preso por deixar o país com \$1 a mais de \$10.000 se não o declarar. Todos têm que levar sempre cartões de identificação e não querem que usemos dinheiro porque não serão capazes de nos controlar e de rastrear cada movimento. O Internal Revenue Service (IRS) - Receita Federal - de repente tem o direito de acessar nossas contas bancárias. A Constituição está sendo gradualmente corroída para abrir o caminho para um governo mundial. Os árabes estão atacando os judeus em Israel. Eles estão construindo a espinha dorsal da internet com novas fibras, e o governo é incapaz de controlar seu rápido crescimento e estrutura feito uma peneira. Um estudo recente mostra que $25 \%$ de todas as mulheres que falam de abuso sexual foram receberam implantes de chips que lhes dão memórias falsamente vívidas de eventos precisos.

No entanto, enquanto a mídia e os poderes instituídos são forças perigosas que espalham a falsa consciência e suprimem o verdadeiro conhecimento, isso é em si parte do plano de Deus. Mesmo os brokers [corretores] do conhecimento na mídia, no governo, na alta tecnologia, nas Nações Unidas e na grande ciência canalizam involuntariamente a verdade. Apesar da ignorância de Hollywood sobre o plano de Deus, seus filmes apocalípticos sobre desastres estão criando imagens das coisas que virão e preparando os não cristãos para a tribulação. Novas tecnologias podem ser usadas para desvendar as verdades secretas da Bíblia. Alguns dizem, por exemplo, que o código da Bíblia pode

\footnotetext{
NT. Termo sem marcação de gênero no inglês.

2 NR. Literalmente, cerca de estacas de madeira. Figurativamente, simboliza a vida ideal americana, aquela de uma família nuclear branca de classe média em um id́lico subúrbio, lugar também idealizado dessa habitação.
} 
ser decodificado lendo cada $20^{\mathrm{a}}$ palavra com a ajuda de computadores. Outros dizem que em algum lugar na Bíblia pode haver pistas sobre a data precisa do arrebatamento. Mas, no final, todos os conhecimentos e as interpretações dos acontecimentos darão lugar à certeza do arrebatamento em si, quando a força de Deus se inscreverá no mundo e libertará os cristãos de sua vigilância. As tecnologias podem começar a rastrear a "magnitude de terremoto" do evento, com as agulhas de seus instrumentos enlouquecendo, mas, à medida que o mundo desmorona ao redor das pessoas, será inútil fazer leituras. As pessoas podem tomar nota do esgotamento da camada de ozônio, do aquecimento global e das epidemias de câncer de pele, mas, no final, os corações dos homens se dobrarão ao rugir dos rios e dos mares. O arrebatamento será em breve.

As sessões de atualização das profecias terminam com orações e comentários amenos de despedida: "Bem, não se preocupe em pagar seus impostos porque ele está chegando em breve, espero que seja este Pentecostes, você nunca sabe". Prepare-se. Prepare-se para aquilo que o Senhor quiser que você faça. Pergunte-lhe o que Ele tem para você todos os dias quando você se levantar.

\section{Heaven's Gate}

Na primavera de 1997, enquanto ouvíamos as pessoas da Calvary Chapel vacilar entre uma justa indignação perante os signos de escalada do mal ao seu redor e a paciência bem-aventurada à luz da vinda próxima do Cristo, as pessoas da Heaven's Gate agiam em outro cenário de fim de tempos, um cenário que fundiu a teoria da conspiração e a cultura da terapia em termos muito mais exigentes. Enquanto a Heaven's Gate se baseava em uma revisão dramática do cenário pré-milenarista de igrejas como a Calvary Chapel, suas raízes intelectuais estavam igualmente nos discursos sobre OVNIs/alienígenas que proliferaram nos Estados Unidos após a Segunda Guerra Mundial.

Histórias de avistamentos de OVNIs e contatos com alienígenas sempre foram tingidas com suspeitas de encobrimento governamental, mas acusações de conspiração, conluios e repressão - preocupações sociais, físicas, psicológicas - foram centrais durante os anos de 1980. Ao mesmo tempo, os discursos sobre OVNIs/alienígenas elaboraram muito suas práticas terapêuticas, e passaram das margens para a corrente dominante da cultura popular americana. Entre as milhares de histórias de avistamentos de OVNIs, Roswell foi o local mais renomado dessas mudanças. Graças a uma série de publicações sensacionais de investigadores de OVNIs (BERLITZ; MOORE, 1980; RANDLE; SCHMIDT, 1991; EBERART, 1991), a minúscula cidade de Roswell no Novo México emergiu da obscuridade de uma história de “disco voador" em 1947 para se tornar a peça central de uma epopeia de extensa cobertura governamental sobre contato extraterrestre (SALER; ZIEGLER; MOORE, 1997, p. 2-29). O processo culminou no "Encontro de OVNIs ‘97" no $50^{\circ}$ aniversário do acidente, que, mais do que tudo, foi "uma celebração do pensamento conspiratório" (DEAN, 1998, p. 191). Na linhagem de histórias de contato alienígenas, as abduções foram o principal ponto de entrada para uma cultura paranoica e terapêutica mais mainstream. Em particular, Budd Hopkins e Whitely Streiber publicaram uma série de livros muito vendidos nos anos de 1980 que revelaram em detalhes vívidos e viscerais 
uma terrível história de contatos alienígenas-humanos que haviam sido duplamente reprimidos como memória pelos alienígenas e como verdade pelos poderes instituídos (HOPKINS, 1981; 1987; STREIBER, 1987; 1989). O processo culminou em 1994, quando o psicólogo e terapeuta de Harvard, John Mack, pronunciou as histórias de abdução por alienígenas como literalmente verdadeiras, acabando, assim, com o bloqueio a evidências sobre encontros alienígenas na academia de elite (MACK, 1994).

Como se obedecessem à crítica de Foucault sobre a hipótese repressiva, quanto mais se dizia que os avistamentos de OVNIs e encontros com alienígenas eram reprimidos, mais eles proliferavam (FOUCAULT, 1980). Na virada do milênio, os discursos sobre OVNIs/ alienígenas haviam se tornado uma grande câmara de compensação para as ansiedades da modernidade tardia sobre as ameaças à agência humana, "a evanescência da verdade", a balcanização da "realidade consensual", o colapso das grandes metanarrativas, a diferença cultural, a origem do significado, e a ampla dispersão da autoridade cultural e política (DEAN, 1998; DERY, 1999; MELLEY, 2000; SALER; ZIEGLER; MOORE, 1997, p. 140-411). Eles também apresentaram um copioso espaço de conjuntura para todos os tipos de expressões idiomáticas, possibilitando conexões por meio de um vasto campo de discursos: viagem espacial; alta tecnologia; informação; ciborgues; vigilância; controle da mente; morte e vida; corpo e espírito; ciência; governo; reprodução; sexualidade; raça; imigração; meio ambiente; colonizar e ser colonizado; medo e desejo; trauma e esperança; catástrofe e salvação; verdade revelada; perseguição; e, é claro, encobrimento (DEAN, 1998; BRYAN, 1995; CURRAN, 1985; DARLINGTON, 1997; HESEMAN; MANTLE, 1997; LEWIS, 1995; LIEB, 1998; PRITCHARD et al., 1994). E incorporaram uma gama completa de terapias: hipnose; canalização; meditação; autoajuda e grupos de apoio; psicoterapia; ironia; humor; embuste; kitsch de consumo; filmes de Hollywood; séries de televisão; e reportagens investigativas.

Como a Calvary Chapel, a Heaven's Gate teve seu início nos anos de 1970. Seus fundadores, Bonnie Lu Nettles (também conhecidos como Peep, a Almirante, Guiné, Ela e Ti) e Marshall Applewhite (também conhecidos como Bo, o Capitão, Porco, Ele e Do), foram criados nas igrejas Batista do Sul e Presbiteriana, respectivamente, mas como adultos se tornaram adeptos de várias artes metafísicas - meditação, canalização de espíritos desencarnados, astrologia, misticismo, teosofia e contatos paranormais com seres espaciais (BALCH, 1995, p. 141-42). Em 1974, sua peculiar mistura de profecia bíblica, metafísica, cultura do disco voador, ficção científica televisiva e biologia de ensino médio se tornou um drama social em desdobramento, no qual eles figuravam não como meros espectadores aguardando o Segundo Advento, mas como atores principais. Applewhite teve uma visão em que percebeu que ele e Nettles eram as duas testemunhas profetizadas em Apocalipse II, e embarcaram em sua missão sabendo que seriam assassinados por espalhar a palavra de Deus, que ressuscitariam dos mortos após três dias e meio, e que subiriam ao céu em uma espaçonave.

Os Dois, como Bo e Peep chamavam a si mesmos na época, começaram a reunir seu rebanho em 1975, convidaram seus seguidores a "sair pela porta de sua vida", separar-se de todos os apegos humanos, preparar-se para a "colheita" de almas que viria, e juntar-se a eles no "reino do Pai" em naves espaciais que viriam para eles pouco depois de Os Dois terem ascendido. Durante quase um ano, o rebanho, com e sem Bo e Peep, acrescentou 
e subtraiu "estudantes", fragmentou e remontou, acampou e vagou, esperando pela "manifestação", o assassinato e a ressurreição, que provaria a verdade da mensagem de Os Dois. No início de 1976, após uma publicidade particularmente ruim na TV em Las Vegas que os fez sentir "como se tivessem sido abatidos pela mídia e a missão estivesse morta", Os Dois disseram a seus cerca de cem estudantes que a Manifestação já havia de fato ocorrido - "nas mãos da mídia". Pouco depois disso, Peep/Ti anunciou que "as portas do Próximo Nível estão fechadas" e que a colheita havia terminado. Era hora de os "estudantes" entrarem na "sala de aula", um período indefinido de crescimento e preparação para vidas de "serviço" no Próximo Nível (BALCH, 1995, p. 154).

O grupo desapareceu de vista do público até 1992, quando ressurgiu brevemente na forma de um website, anúncios em jornais, transmissões de televisão e reuniões públicas, a fim de fazer uma "oferta final" àqueles que se juntariam a eles para a "decolagem" que estava iminente. Tendo reunido algumas "ovelhas perdidas", o Heaven's Gate, como o grupo já era conhecido, desapareceu novamente até o notório dia do final de março de 1997, quando 38 corpos foram encontrados apodrecendo em uma casa rica no subúrbio de San Diego. Visto de fora, foi "o maior suicídio em massa da história dos Estados Unidos". Visto por dentro, o capitão (Bo, Do, Applewhite) e sua tripulação tinham deixado seus veículos terrestres para trás e se juntaram ao almirante (Peep, Ti, Nettles, que terminou seu trabalho no nível humano e partiu em 1985) em uma nave espacial escondida na cauda do cometa Hale-Bopp para sua viagem até o Próximo Nível.

O suicídio do grupo combinou-se com outros sinais indicadores de que era um "culto" para garantir o status do Heaven's Gate como fenômeno ultramarginal. O grupo e seu espetacular final figurou como um grande sinal dos tempos em vários cenários paranoicos, como "O ano 2000 se aproxima e está tirando todos os malucos de seus esconderijos" (TIME, 1997) ou "Este novo culto híbrido [surgiu] de uma mistura de técnicas de comunicação humana e a mais recente, mais atualizada e mais poderosa tecnologia de comunicação de massa na história humana [...] a Rede Mundial de Computadores" (CONWAY; SIEGELMAN, 1997). Os proeminentes especialistas em OVNIs/alienígenas denunciaram a Heaven's Gate não apenas como um culto suicida, mas também por sua reverência aos alienígenas, ou seja, às almas do Próximo Nível, que viajavam em naves espaciais e cujos corpos pareciam pequenos alienígenas cinzas. Falando na celebração de Roswell em 1997, Budd Hopkins rejeitou qualquer reivindicação sobre "bons, benevolentes, ecoalienígenas transformadores", igualando aqueles que fazem tais reivindicações com os suicídios do Heaven's Gate: "Para qualquer um aceitar a idéia de que devemos ignorar nossos semelhantes e olhar para os ocupantes de OVNIs como a fonte final de sabedoria ecológica e crescimento espiritual, é, infelizmente, dar um passo no mesmo caminho" (DEAN, 1998, p. 195).

Hopkins repreendeu a Heaven's Gate por sua "pronoia", sua convicção de que os alienígenas estavam querendo nos ajudar, não nos ferir (DERY, 1999, p. 13), mas, como veremos, sua paranoia era igualmente pronunciada. Embora esteja longe do mainstream, o Heaven's Gate participou plenamente da integração do pensamento paranoico e da cultura terapêutica durante os anos de 1980 e apresenta um exemplo requintado de sua fusão. Sua metanarrativa cósmica, tal como apareceu em várias páginas da web durante os anos de 1990 (veja as entradas do Heaven's Gate na lista de referência) tinha se 
tornado muito mais apocalíptica e conspiratória do que nos anos de 1970, bem como muito mais efetivamente terapêutica, proporcionando uma voz pessoal confiante, um ponto de vista histórico complexo e fortes linhas de enredo, personagens e motivações.

No lado mais leve, Do e seus alunos nos dizem que "o reino humano foi criado como um trampolim entre o reino animal e o verdadeiro Reino de Deus", o Nível Acima do Humano, que era um lugar físico, não um reino espiritual. O reino humano é composto de "plantas ou recipientes de sementes de mamíferos", enquanto o Reino do Nível Seguinte é composto de "recipientes para almas, não mamíferos, não portadores de sementes". As almas evoluem por meio de uma série de encarnações nos corpos dos mamíferos e progridem pela perda de características e comportamentos humanos/ mamíferos - sexualidade, gênero e todos os outros vícios e laços - por meio da tutoria de um membro, ou representante, do Reino de Deus que já passou pelo processo. A Terra é, portanto, um “jardim" de plantas (recipientes, veículos) para almas, que são colhidas de tempos em tempos pelos Representantes do Próximo Nível. O corpo de Jesus foi preparado, ou etiquetado, ao nascer e encarnado no momento de seu batismo pela alma de um Representante do Próximo Nível que tinha vindo à Terra para colher algumas almas selecionadas. Do e Ti foram, como Jesus, Representantes do Próximo Nível, marcados no nascimento e encarnados por almas no início dos anos de 1970. Os corpos de sua tripulação foram, como os dos discípulos de Jesus (sua tripulação), também marcados ao nascer; em meados dos anos de 1970 e início dos anos de 1990, eles foram encarnados por almas do Próximo Nível que chegaram em naves espaciais (que os humanos chamavam de OVNIs e discos voadores). Durante duas décadas, a tripulação usou seus corpos humanos como casulos, sofrendo a metamorfose necessária para sua transição para corpos sem gênero, assexuados, não desejáveis, telepáticos, eternos, presos a cada um, e apenas a um Membro Ancião, e vivendo vidas de serviço ao Próximo Nível. Nos anos de 1990, Do começou a receber sinais cada vez mais claros de que seu tempo de sala de aula estava quase no fim, embora ele não soubesse por algum tempo se eles subiriam corporalmente em uma nave espacial que pousaria na Terra ou deixariam seus veículos terrestres, seus corpos de carne, para trás e ascenderiam como almas desencarnadas (Heaven's Gate, "Planet about to Be Recycled").

No lado mais escuro, a "jardinagem" do Próximo Nível na Terra há muito tempo tinha sido desafiada e corrompida por "malévolas raças alienígenas do espaço" que se apresentavam aos humanos como "Deuses". Eles são "luciferianos", descendentes de membros do Próximo Nível que caíram há muitos milhares de anos, e eles são “OS MAIORES INIMIGOS dos humanos. Eles mantêm os humanos em escravidão desconhecida apenas para satisfazer suas próprias necessidades. Eles não podem verdadeiramente criar [o Próximo Nível é o único lugar de onde as almas, a vida e todos os criadores se originam], mas desenvolvem raças e recipientes pela manipulação genética e hibridização; eles fazem acordos com governos humanos para se engajar em experiências biológicas (por meio de abduções) em troca de tecnologia avançada". Os luciferianos mantêm os humanos na escuridão por meio do seu controle sobre as religiões, acima de tudo o Cristianismo, e da família, sexualidade e gênero. Eles cuidam para que "por meio da 'norma social' [o maior 'culto' luciferiano que existe] o homem continue a não aproveitar a possibilidade de avançar além do humano" (Heaven's Gate, 
“UFO Cult' Resurfaces"). Quando membros do Nível Acima do Humano estão presentes, as forças anti-Reino "'aumentam o calor" na área do comportamento dos mamíferos", ligando "almas humanas a este mundo por meio: de uma preocupação com a sexualidade (indulgência em todos os prazeres/vícios dos sentidos humanos); reprodutividade (família); serviço ao reino humano (dentro da estrutura de endividamento e crédito); e responsabilidade 'moral' incontestável para com sua família, comunidade, raça, nação e seus conceitos religiosos inconscientemente distorcidos" (Heaven's Gate, "UFO Cult' Resurfaces", "Organized Religion"). As forças opostas foram tão bem-sucedidas que "o joio tomou conta do jardim e realmente estragou sua utilidade para além do conserto - é hora de a civilização ser reciclada - 'enterrada'" (Heaven's Gate, “Overview of Present Mission").

O herói modal nos dramas de conspiração americanos do pós-guerra - isto é, em teorias que são atualizadas na prática e habitadas, que se tornam verdadeiros mundos paralelos - é o indivíduo masculino solitário que percebe que o sistema é maligno e luta poderosamente para "sair" dele, às vezes sozinho, às vezes com aqueles que pensam de modo similar. Tais figuras - Timothy McVeigh, Theodore Kaczynski, as milícias brancas - podem ser vistas como afirmando vigorosamente noções masculinistas de autonomia individual e autocontrole contra forças políticas, sociais e técnicas adversárias. Mas a paranoia do pós-guerra acomodou outros tipos de respostas ao desafio das noções liberais do indivíduo e da agência humana, incluindo aquelas como Heaven's Gate que, efetivamente, rejeitaram ativamente o individualismo liberal. Do e seus estudantes simpatizavam com aqueles que desprezavam publicamente "o sistema" e tentavam viver "fora" dele. Eles pensavam que humanos como Randy Weaver em Ruby Ridge e os Branch Davidians de Waco estavam tentando fugir e, portanto, talvez não forem "enterrados" com o resto da humanidade (Heaven's Gate, "Last Chance"). Mas, por não terem recebido nenhuma instrução de Representante do Próximo Nível e, portanto, não terem abandonado seus vícios, desejos e laços mamíferos, tais humanos ainda não estavam prontos para avançar para o Reino de Deus e teriam que passar por mais reencarnações. A busca não era simplesmente para escapar do "controle social"; era para escapar do controle social "humano" e para entrar e se submeter totalmente à socialização do "Próximo Nível". A Heaven's Gate assim reencantou duplamente o controle social: por um lado, como o mal, por meio das raças alienígenas luciferianas do espaço; e, por outro, como benevolente, por meio das pequenas almas cinzentas do Próximo Nível.

Os discursos sobre OVNIs/alienígenas e a cultura pós-guerra da paranoia em geral são espaços culturais limítrofes - sistemas nervosos - que acomodam uma variedade de reações às ansiedades dos tempos. Alguns deles são frouxos e de baixo custo; outros, especialmente os dramas conspiratórios, as paranoias habitáveis, como a da Heaven's Gate, são rígidos, absorventes, intensos e exigentes. A requisição de entrada para o Heaven's Gate era a separação total do mundo - deixe para trás família, amor, sexo, trabalho, posses materiais, nomes pessoais e identidades - "tudo, exceto comida e líquidos suficientes para sustentar seu veículo enquanto ele estiver aqui, e descanso suficiente para dar-lhe a força que precisa enquanto estiver em uma atmosfera decadente como a da Terra. [...] Qualquer outra coisa, seja o desejo de tocar violino ou pregar um sermão ou cuidar de uma criança, qualquer coisa deste mundo, você deve superar" (STEIGER; HEWES, 1997, p. 153-54). 
No início, esperava-se que os estudantes, após abandonarem tudo, descobrissem por conta própria, por meio do contato direto com o Próximo Nível, o que mais precisavam fazer para completar o processo de superação. Depois, no verão de 1976, Os Dois os reuniram em um acampamento em Wyoming e os lançaram em quase duas décadas de terapias metamórficas orquestradas minuciosamente, ou "disciplinas". Essas disciplinas são geralmente examinadas como técnicas de lavagem cerebral, algumas muito comuns, outras novinhas em folha, mas Do as apresentava como momentos consumados de escolha nos quais os estudantes decidiam repetidamente renunciar a seus símbolos de agência humana e autonomia em favor de alcançar o próximo nível de consciência. A ninguém foi dito para fazer qualquer coisa; todos eram livres para escolher a cada momento se deveriam seguir as instruções do Próximo Nível; se optassem por segui-las, subiriam; se não, não.

Os estudantes usavam capuzes "para aprender sobre os modos 'enganosos' de suas personalidades visuais". Seus dias eram organizados em tarefas "designadas" a cada 12 minutos - "cada pessoa indo fisicamente a um determinado lugar a cada período para concentrar-se em seu desejo de servir" (Heaven's Gate, "'88 Update'"). A cada estudante era designado um "parceiro de verificação", a quem eles consultavam antes de tomar qualquer decisão. Foram-lhes dados novos nomes. Eles se tornaram meticulosos escrivões e preenchiam seus diários de sentimento a cada 12 minutos. Havia jejuns frequentes, incluindo um de três meses com um "limpador mestre" composto de limonada, pimenta caiena e xarope de ácer. Os estudantes entraram em regimes prolongados de silêncio chamados "tempo do túmulo". Foi-lhes pedido que abandonassem todos os vícios não apenas sexo, álcool, cigarros e drogas, mas gostos e aversões, hábitos, opiniões, julgamentos, formas de se expressar e traços de personalidade - "como ser crítico em relação aos outros ou se apegar a si mesmo, ter respostas negativas às situações, precisar falar constantemente, ter as coisas à sua maneira ou em um horário específico, ou precisar de afeto humano ou atenção" (Heavenıs Gate, "Total Overcomers"). Finalmente, "diretrizes comportamentais" detalhadas sedimentaram ainda mais um regime escrupuloso de autovigilância. Havia "17 passos" para entrar na sala de aula, começando com "Pode você seguir instruções sem acrescentar sua própria interpretação" (Heaven's Gate, "The 17 Steps"). As "diretrizes mais avançadas para aprendizagem de controle e restrição" definiam três grandes ofensas (engano, sensualidade, e conscientemente quebrar uma instrução) e mais de 30 ofensas menores (por exemplo, ter "curiosidade inapropriada", "ficar na minha própria cabeça, ter pensamentos privados" e "identificar-se com influências - usando o pronome 'eu' ou 'me' em aplicação a uma ofensa em vez de reconhecer que era uma influência usando-me") (Heaven`s Gate, "Major and Lesser Offenses").

No início, tais terapias eram entendidas como exercícios que permitiam aos humanos evoluir para membros do Próximo Nível. Mais tarde, Do, ou Ti, ou Os Dois, perceberam que seus alunos já tinham, como eles mesmos, sido encarnados - eles "não eram humanos recrutados por Ti e Do [...] mas eram membros do Próximo Nível mesmo antes de os conhecerem" (Heaven's Gate, "88 Update"). Eram todos eles "walk-ins", todos alienígenas que ocupavam (aprisionados em) corpos humanos. Se as noções de subjetividade liberal se apegam a um senso de interioridade, autocontrole e autossuficiência, a um senso de que o indivíduo é "um agente racional e motivado com um núcleo interior protegido 
de crenças, desejos e memórias" (MELLEY, 2000, p. 12), os membros da Heaven's Gate procuraram desocupar essa subjetividade tanto quanto procuraram evacuar a sociedade moderna. Ou quase tanto. Pois conservaram a essência do individualismo liberal, a intenção individual (MELLEY, 2000, p. 30), em seu mandato paradoxal de escolher perpetuamente não ter escolhas.

Enquanto os membros da Heaven's Gate se tornaram, como os cristãos da Calvary Chapel, adeptos a ler o mundo - e os céus - que os rodeavam buscando por "signos" de que suas profecias estavam se tornando realidade, esse não era seu método mais típico de produzir sentido. Seu forte, sua genialidade peculiar, estava em oscilar entre uma série de vernáculos - cristãos, OVNIs/contactados, Nova Era, ficção científica, biologia, jardinagem, ensinamentos - formando assim um discurso híbrido no qual as costuras estavam em primeiro plano. De fora, seus movimentos semioticos pareciam paródicos; de dentro, pareciam revelação. Sua linguagem era abertamente dupla, de modo a destacar a intertextualidade e a tradução no processo de produção de sentido. Com sua incessante explicitação de conexões e entrelaçamento de termos, Ti e Do ensinavam a seus estudantes um modo literário de atenção. Eles mostraram a eles como as coisas estavam interligadas, não apenas que elas estavam conectadas. Na verdade, eles lhes mostraram como conectar as coisas, como converter semelhanças por meio de fronteiras de diferença em semelhanças desde sempre ligadas pela similitude. Eles thes ensinaram como converter metáforas em metonímias. Como encantar, ou reencantar, o mundo.

A repetição interminável de expressões idiomáticas geminadas e torcidas apareceu, não apenas na linguagem da Heavens' Gate, mas também em suas práticas e aparências. Os líderes do grupo eram, naturalmente, um par separado por pequenas diferenças e eram assim chamados, alternadamente, Bo e Peep, Almirante e Capitão, Ele e Ela, Winnie e Pooh, Tiddly e Wink, Nicom e Poop, Chip e Dale, Pig e Sow, Ti e Do, ou, simplesmente, Os Dois. E as referências culturais dos anos de 1970 foram muito além de Star Trek e Star Wars para produzir um sentido complexo de duplicação ou de referência cruzada, intertextualidade, hipertextualidade - entre o então e o agora. A celebração antifamília, antigênero, radical e igualitária da similitude como forma de comunhão com o outro realizada pela Heaven's Gate se espelhava no monasticismo e no misticismo, mas também na contracultura hippie. Até mesmo sua antissexualidade radical, que parecia certamente refletir os anos de 1990, estava ligada à cultura jovem dos anos de 1970 na forma com que era tematizada como uma busca por uma espécie de sexualidade inocente, primordial e o desejo pela intimidade da alteridade indiferenciada. "A virgindade", Do dizia, "pode ser recuperada" (Heaven's Gate, "88 Update"). Do, ele mesmo era uma figura paternal muito ao estilo de 1970, um pai suave e avuncular, uma mistura ao estilo Dr. Spock de rotinização e permissão, de Mr. Rogers e Timothy Leary. Na verdade, ele era um pouco parecido com Mr. Rogers, e soava um pouco como ele também. Também se parecia com um Timothy Leary sem cabelos, uma semelhança que se manifestou na época do suicídio pelo que só podemos esperar que tenha sido uma coincidência - o lançamento das cinzas de Timothy Leary, juntamente com as cinzas do inventor de Star Trek, Gene Roddenberry, no espaço na mesma semana em que o Heaven's Gate subiu para o Próximo Nível.

A essa lista de alusões aos anos de 1970 - de assombramento, canalização, duplicação, déjà vus, momentos de repetição temporal - podemos também acrescentar os Grateful 
Dead. A linguagem da cultura hippie/da droga ligava o Heaven's Gate aos Dead, bem como a Timothy Leary. Os pensamentos, por exemplo, enviados aos estudantes do Next Level eram chamados de flashes e hits, termos outrora associados às atividades quintessenciais dos anos de 1970, viagens de LSD e fumar maconha. A maior mímica dos Grateful Dead realizada pela Heaven's Gate foi sua qualidade de trupe de viagem. O serpentear pelo país, o processo contínuo de quebra e de reagrupamento, a aparente amorfidade antiorganizacional e a ausência de placidez, tudo isso ecoava os Dead. Os movimentos da Heaven's Gate tinham um nível de voo que os Dead nunca tiveram, uma margem que lembrava ainda mais um fantasma dos anos de 1970 - o programa de televisão The Fugitive.

O suicídio em massa da Heaven's Gate foi de fato o último momento de uma longa sucessão de desaparecimentos repentinos, fugas, separações, esconderijos e disfarces. Marshall Applewhite e Bonnie Lu Nettles desapareceram, ao se tornarem Bo e Peep, das vidas de suas já afastadas famílias, amigos e amantes. Durante o ano de 1975, eles reuniram ao acaso seu grupo de seguidores, e grupos de cinco, dez e 20 pessoas "desapareceram de repente" de suas cidades após se encontrarem com Bo e Peep. Alguns estudantes nunca mais contataram suas famílias ou amigos; outros ligaram para casa eventualmente de telefones públicos ou lhes enviaram cartões postais carimbados em cidades distantes de onde viviam. Eles assumiram novos nomes, não um, mas dois, ou três, ou mais. Quando finalmente se materializaram de forma duradoura para o mundo ver, foi no ciberespaço, o último não lugar, ou melhor, a zona de incontáveis lugares virtuais. E, mesmo assim, eles registraram suas páginas na web sob nomes e endereços falsos.

Os fugitivos são uma espécie de proscritos; eles ocupam espaços fora da lei. Não está claro, às vezes mais, às vezes menos, se os fugitivos estão no certo ou no errado e, portanto, sua fuga chama atenção e problematiza o sistema, qualquer que seja o sistema que atribua valor, significado, credibilidade, autoridade e direitos de tal forma que force uma fuga. Algo que é fugitivo também é algo fugaz ou que foge ao alcance; algo evanescente, de curta duração, desvanecendo-se ou tornando-se apagado (OED) [Oxford English Dictionary]. Talvez os membros da Heaven's Gate tivessem preferido não deixar nada para trás, nem mesmo seus corpos humanos, embarcando em uma espaçonave para o Próximo Nível da Terra, mas isso não funcionou dessa maneira. Por outro lado, ao desejarem a morte inevitável - talvez tenham ganho, ou recuperado, "a intenção suicida esgotada do sujeito sociológico", o que Durkheim chamou de "tentativa de explicar o suicídio sem recorrer ao motivo individual" (MELLEY, 2000, p. 30, 28). Mas suas "declarações de saída" não sugerem que a agência individual estivesse em jogo. Em vez disso, como no caso de seu nomadismo, o objetivo, além de levar suas almas a bordo da nave para o Próximo Nível, era chamar a atenção para a falta de sentido do que estavam deixando para trás, demonstrar que "o verdadeiro significado de 'suicídio' é voltar-se para o Próximo Nível quando ele está sendo oferecido" ("Exit Statements").

O estudante Glnody escreveu, "Escolher sair deste veículo ou corpo humano emprestado e ir para casa, para o Próximo Nível, é uma oportunidade para eu demonstrar minha lealdade, compromisso, amor, confiança e fé em Ti e Do e no Próximo Nível [...] Não há vida aqui neste mundo humano. Este planeta se tornou o planeta dos mortosvivos. As plantas humanas caminham, falam, fazem carreira, procriam, etc., mas não 
há vida nelas [...] Suicídio seria afastar-se dessa incrível oportunidade que me foi dada, virar as costas para o Próximo Nível e para a vida que eles estão oferecendo". Já Srrody escreveu: "Enquanto o cometa Hale-Bopp traz o encerramento desta visita, talvez até mesmo desta civilização, estou tão cheio de alegria - não só por mim e meus colegas de classe, mas com o orgulho que só um filho pode ter por Seu Pai [Do], que fez um milagre do Próximo Nível: que qualquer um de nós tenha conseguido sair vivo deste mundo" ("Earth Exit Statements").

\section{Pós-Escrito}

A teoria da conspiração não é um conjunto aberto de "práticas de leitura", mas uma estrutura particular de sentimento. É um sistema nervoso, uma sensibilidade partida, um espaço cultural internamente dividido que tem força, que gera, assim como registra, as contradições das transformações sociais contemporâneas. Preocupada com questões de agência individual, e às vezes ansiosa por fugir, ela sabe no fundo que não há "fora" para as influências sociais/maléficas na Terra. Embora sem esperança por uma cura política, ela a busca de qualquer maneira na forma de uma perfeita racionalização da relação entre o eu e o mundo. Como um discurso metacultural - insistindo em dilemas fundamentais e abstratos do ideal e do real, do bem e do mal, da criação e da destruição, da esperança e do desânimo, da pureza e da poluição, do mistério e da minuciosidade - a teoria da conspiração trabalha ativamente no e com o mundo, se não o cosmos, em busca de suas curas. A Calvary Chapel racionalizava o eu e o mundo, vasculhando infinitamente os sinais dos tempos, enquanto a Heaven's Gate canalizava e dramatizava um mistura de histórias e tropos - ambos fortemente baseados "na mídia", na televisão, rádio, jornais, revistas e internet como suas matérias-primas. Suas paranoias são/eram não ideologias ou crenças, mas práticas, marcadamente inventivas, amplas e eficazes, que penetram profundamente no sujeito moderno como modos de agência e flutuam como um éter em um mundo composto de múltiplas, contraditórias, paradoxais, instáveis, mas intermináveis influências. Esse é o Iluminismo com uma vingança. É também o traço assombroso e a lembrança das forças ocultas e das sensibilidades excluídas que agora permeiam os campos de força da vida social e cultural e saturam o sentido do eu sintomático no mundo.

\section{Referências}

BALCH, Robert. Waiting for the Ships: Disillusionment and the Revitalization of Faith in Bo and Peep's ufo Cult. In: JAMES, R. Lewis (ed). The Gods Have Landed: New Religions from Other Worlds. Albany: State University of New York Press, 1995. p. 137-166.

BALMER, Randall. Mine Eyes Have Seen the Glory: a Journey into the Evangelical Subculture in America. Oxford: Oxford University Press, 1993.

BALMER, Randall; TODD JR., Jesse T. Calvary Chapel, Costa Mesa, California. In: JAMES, Wind; JAMES, Lewis. (ed.). American Congregations: Portraits of Twelve Religious Communities. Chicago: University of Chicago Press, 1994. p. 442-460. 
BARKUN, Michael. Politics and Apocalypticism. In: STEIN, Stephen. (ed.). The Encyclopedia of Apocalypticism. New York: Continuum, 1998. p. 442-460.

BERLANT, Lauren. Face of America and the State of Emergency. In: NELSON, Cary; GAONKAR, Dilip P. (ed.). Disciplinarity and Dissent in Cultural Studies. New York: Routledge, 1996. p. 397- 439.

BERLITZ, Charles; MOORE, W. L. The Roswell Incident. New York: Grosset and Dunlap, 1980.

BRYAN, C. D. B. Close Encounters of the Fourth Kind: Alien Abduction, ufos, and the Conference at mit. New York: Knopf, 1995.

BUCK-MORSS, Susan. Aesthetics and Anaesthetics: Walter Benjamin's Artwork Essay Reconsidered. October, [s.l.], n. 62, p. 3-41, 1993.

BUCK-MORSS, Susan. The City as Dreamworld and Catastrophe. October, [s.l.], n. 73, p. 3-26, 1995.

BUTLER, Judith. The Psychic Life of Power: Theories in Subjection. Stanford: Stanford University Press, 1997.

CONWAY, Flo; SIEGELMAN, Jim. Exclusive: Nation's Leading Cult Experts Begin a Web Diary as the Heaven's Gate Story Unfolds. 1997. Disponível em: http://www.zdnet.com/ yil/ higher/cultc011.html. Acessado periodicamente entre: 1997-1998. [NR: página não está mais disponível].

CURRAN, Douglas. In Advance of the Landing: Folk Concepts of Outer Space. New York: Abbeville, 1985.

DARLINGTON, David. Area 51: The Dreamland Chronicles. New York: Henry Holt, 1997.

DEAN, Jodi. Aliens in America: Conspiracy Cultures from Outerspace to Cyberspace. Ithaca: Cornell University Press, 1998.

DERY, Mark. The Pyrotechnic Insanitarium: American Culture on the Brink. New York: Grove, 1999.

EBERART, George M. (ed.). The Roswell Report. Chicago: Hynek Center for UFO Studies, 1991.

FELDMAN, Allen. On Cultural Anaesthesia: From Desert Storm to Rodney King. American Ethnologist, [s.l.], v. 21, n. 2, p. 404-418, 1994.

FENSTER, Mark. Conspiracy Theories: Secrecy and Power in American Culture. Minneapolis: University of Minnesota Press, 1999.

FOUCAULT, Michel. The History of Sexuality. New York: Vintage; Random House, 1980. V. 1.

FOX, Richard; LEARS, Jackson. Introduction. In: FOX, Richard; LEARS, Jackson. (ed.). The Culture of Consumption. New York: Random House, 1983. p. 3-45.

GIBSON, James William. Warrior Dreams: Paramilitary Culture in Post-Vietnam America. New York: Hill and Wang, 1994.

GRAHAM, Allison. Are You Now or Have You Ever Been? Conspiracy Theory and the X-Files. In: LAVERY, David; HAGUE, Angela; CARTWRIGHT, Marla. (ed.). Deny All Knowledge: Reading the X-Files. Syracuse: Syracuse University Press, 1996. p. 52-62.

HARDING, Susan. The Book of Jerry Falwell: Fundamentalist Language and Politics. Princeton: Princeton University Press, 2000.

HEAVEN'S GATE. Webpages. [Acesso entre 1997-1998]. 
HEAVEN'S GATE. Earth Exit Statements. Acesso entre: 1997-1998. [NR: Não está mais disponível].

HEAVEN'S GATE. 88 Update - the ufo Two and Their Crew: A Brief Synopsis.-Disponível em: http://www. zdnet.com/yil/higher/heavensgate/book/3-3.htm. Acesso entre: 1997-1998. [NR: Não está mais disponível].

HEAVEN'S GATE. Exit Statements/Our Position against Suicide. Disponível em: http:// www.zdnet.com/yil/ higher/heavensgate/letter.htm. Acesso entre: 1997-1998. [NR: Não está mais disponível].

HEAVEN'S GATE. How and When Heaven's Gate May Be Entered: An Anthology of Our Materials and Table of Contents. Disponível em: http://www.zdnet.com/yil/higher/heavensgate/ book/book.htm. Acesso entre: 1997-1998. [NR: Não está mais disponível] HEAVEN'S GATE. Index. Disponível em: http://www.zdnet.com/yil/higher/heavensgate/index.html. Acesso entre: 1997-1998. [NR: Não está mais disponível].

HEAVEN'S GATE. Last Chance to Evacuate Earth before It's Recycled (Edited Transcript of Videotape - September 29, 1996). Disponível em: http:/www.zdnet.com/yil/higher/heavens gate/vt092996.html. Acesso entre: 1997-1998. [NR: Não está mais disponível].

HEAVEN'S GATE. Major and Lesser Offenses. Disponível em: http://www.zdnet.com/yil/ higher/heavens gate/book/2-5.htm. Acesso entre: 1997-1998. [NR: Não está mais disponível].

HEAVEN'S GATE. 95 Statement by an E.T. Presently Incarnate. Disponível em: http:// www.zdnet.com/yil/ higher/heavensgate/book/1-4.htm. Acesso entre: 1997-1998. [NR: Não está mais disponível].

HEAVEN'S GATE. Organized Religion (Especially Christian) Has Become the Primary Pulpit for Misinformation and the 'Great Cover-Up. Disponível em: http://www.zdnet. com/yil/higher/heavensgate/book/6 - 6.htm. Acesso entre: 1997-1998. [NR: Não está mais disponível].

HEAVEN'S GATE. Overview of Present Mission. Disponível em: http:/www.zdnet.com/yil/ higher/heavens gate/book/05.htm. Acesso entre: 1997-1998. [NR: Não está mais disponível].

HEAVEN'S GATE. Planet about to Be Recycled; Your Only Chance to Survive: Leave with Us (Edited Transcript of Videotape - October 5, 1996). Disponível em: http://www.zdnet. com/yil/ higher/heavensgate/vt100596.html. Acesso entre: 1997-1998. [NR: Não está mais disponível].

HEAVEN'S GATE. The 17 Steps. Disponível em: http://www.zdnet.com/yil/higher/ heavensgate/book/2-5. htm. Acesso entre: 1997-1998. [NR: Não está mais disponível].

HEAVEN'S GATE. Total Overcomers Classroom Admission Requirements. Disponível em: http://www. zdnet.com/yil/higher/heavensgate/book/5-6.htm. Acesso entre 1997-1998. [NR: Não está mais disponível].

HEAVEN'S GATE. Transcripts of Two Recent Videos. Disponível em: http://www.zdnet. com/yil/higher/ heavensgate/latest.htm. Acesso entre: 1997-1998. [NR: Não está mais disponível].

HEAVEN'S GATE. Ufo Cult' Resurfaces with Final Offer. Disponível em: http://www. zdnet.com/yil/ higher/heavensgate/book/5-2.htm. Acesso entre 1997-1998. [NR: Não está mais disponível].

HESEMANN, Michael; MANTLE, Philip. Beyond Roswell: The Alien Autopsy Film, Area 51, and the U.S. Government Cover-Up of ufos. London: Michael O'Mara, 1997.

HOPKINS, Budd. Missing Time: a Documented Study of ufo Abductions. New York: Richard Marek, 1981. 
HOPKINS, Budd. Intruders: The Incredible Visitations at Copley Woods. New York: Random House, 1987.

IVY, Marilyn. Have You Seen Me? Recovering the Inner Child in Late Twentieth-Century America. Social Text, [s.l.], v. 37, p. 227-252, 1993.

IVY, Marilyn. Discourses of the Vanishing: Modernity, Phantasm, Japan. Chicago: University of Chicago Press, 1995.

KELLY, Michael. The Road to Paranoia. New Yorker, [s.l.], p. 60-75, 19 June, 1995.

LEWIS, Fred. The New Antiterrorism. New York Review of Books, [s.l.], v. 46, n. 2, p. 24, 1999.

LEWIS, James R. (ed.). The Gods Have Landed: New Religions from Other Worlds. Albany: State University of New York Press, 1995.

LIEB, Michael. Children of Ezekiel: Aliens, ufos, the Crisis of Race, and the Advent of End Time. Durham: Duke University Press, 1998.

LUTZ, Tom. American Nervousness, 1903: An Anecdotal History. Ithaca: Cornell University Press, 1991.

MACK, John E. Abduction: Human Encounters with Aliens. New York: Scribner's, 1994.

MARCUS, George (ed.). Paranoia within Reason: a Casebook on Conspiracy as Explanation. Chicago: University of Chicago Press, 1999.

MARSDEN, George. Fundamentalism and American Culture: The Shaping of TwentiethCentury Evangelicalism, 1870-1925. New York: Oxford University Press, 1980.

MELLEY, Timothy. Empire of Conspiracy: The Culture of Paranoia in Postwar America. Ithaca: Cornell University Press, 2000.

MILLER, Donald. Reinventing American Protestantism: Christianity in the New Millennium. Berkeley and Los Angeles: University of California Press, 1997.

PFEIL, Fred. Sympathy for the Devil: Notes on Some White Guys in the Ridiculous Class War. New Left Review, [s.l.], v. 213, p. 115-124, 1995.

PRITCHARD, Andrea et al. (ed.). Alien Discussions: Proceedings of the Abduction Study Conference. Cambridge, Mass.: North Cambridge, 1994.

RANDLE, Kevin D.; SCHMIDT, Donald R. The ufo Crash at Roswell. New York: Avon, 1991. ROBERTSON, Pat. The New World Order. Dallas: Word, 1991.

SALER, Benson; ZIEGLER, Charles A.; MOORE, Charles B. UFO Crash at Roswell: The Genesis of a Modern Myth. Washington, D.C.: Smithsonian Institution Press, 1997.

SCHOEPFLIN, Rennie B. Apocalypse in an Age of Science. In: STEIN, Stephen. (ed.). The Encyclopedia of Apocalypticism. New York: Continuum, 1998. p. 108-139.

SMITH, Chuck. Time Is Short, Cor. 7:29-32. The Word for Today, tape 8653. Costa Mesa, Calif.: Calvary Chapel Ministries, 1997.

STEIGER, Brad; HEWES, Hayden. Inside Heaven's Gate: The ufo Cult Leaders Tell Their Story in Their Own Words. New York: Signet, 1997.

STREIBER, Whitley. Communion: A True Story. New York: [s.n.], 1987.

TAUSSIG, Michael. The Nervous System. New York: Routledge, 1992.

TERKEL, Studs. The Great Divide: Second Thoughts on the American Dream. New York: Pantheon, 1988.

TIME. Special Report: Inside the Web of Death. 7 April, p. 28-47, 1997. 
WEBER, Max. The Protestant Ethic and the Spirit of Capitalism. New York: Scribner's, 1958. WEBER, Timothy. Living in the Shadow of the Second Coming. Grand Rapids, Mich.: Zondervan, 1983.

WILLIAM, Morrow. Transformation: The Breakthrough. New York: Avon, 1989.

WILSON, Robert Anton; MILL, Miriam Joan. Everything Is Under Control: Conspiracies, Cults, and Cover-Ups. New York: Harper, 1998.

* Este artigo foi publicado originalmente como WEST, H.; SANDERS, T. (ed.). Transparency and conspiracy: ethnographies of suspicion in the new world order. Durham: Duke University Press, 2003. p. 258-286.

\section{Susan Harding}

Professora Emérita de Antropologia na Universidade da Califórnia, Santa Cruz. É autora de The Book of Jerry Falwell (Princeton University Press, 2000), tendo publicado amplamente sobre cristianismo fundamentalista, movimentos sociais e reforma cultural, narrativa e retórica. Atualmente trabalha na conclusão de The Book of Secular America.

Endereço profissional: Anthropology Department, UC Santa Cruz, 1.156 High Street, Santa Cruz, CA. 95064 USA.

E-mail: hard@ucsc.edu

\section{Kathleen Stewart}

Professora do Departamento de Antropologia e do Americo Paredes Center for Cultural Studies da Universidade do Texas em Austin. É autora de A Space on the Side of the Road: Cultural Poetics in an 'Other" America. (Princeton University Press, 1996); Ordinary Effects (2007) e The Hundreds, com Lauren Berlant (Duke University Press, 2019). Escreve sobre afeto, o ordinário, o sensorial e modos de etnografia. Endereço profissional: Department of Anthropology, University of Texas at Austin, WCP 4.102; 2.201 Speedway Stop C3200, Austin, TX. 78712 USA.

E-mail: kstewart@austin.utexas.edu

\section{Bruno Reinhardt (Tradutor)}

Mestre em Antropologia pela UnB, Doutor em Antropologia pela Universidade da Califórnia, Berkeley. Professor do Departamento de Antropologia da UFSC.

Endereço profissional: Departamento de Antropologia, CFH, Campus Universitário Reitor João David Ferreira Lima, Trindade, Florianópolis, SC. CEP: 88040-900.

E-mail: bmnreinhardt@gmail.com

ORCID: https://orcid.org/0000-0003-3853-5927

\section{Vânia Z. Cardoso (Revisora de tradução)}

Mestre e doutora em antropologia pela Universidade do Texas em Austin. Professora Associada do Departamento de Antropologia da UFSC.

Endereço profissional: Departamento de Antropologia, CFH, Campus Universitário Reitor João David Ferreira Lima, Trindade, Florianópolis, SC. CEP: 88040-900.

E-mail: vania.cardoso@ufsc.br

ORCID: https://orcid.org/0000-0003-2554-1615

\section{Como referenciar este artigo:}

HARDING, Susan; STEWART, Kathleen. Ansiedades de Influência: Teoria da Conspiração e Cultura Terapêutica na América do Milênio. Tradução de Bruno Reinhardt e revisão de Vânia Z. Cardoso. Ilha - Revista de Antropologia, Florianópolis, v. 23, n. 3, p. 214-239, setembro de 2021. 